\title{
Complexities of Immigrant Identity: Issues of Literacy, Language, and Culture in the Formation of Identity
}

\author{
Bita H. Zakeri
}

\begin{abstract}
Identity is an issue that everyone struggles with on a daily basis while constantly changing, adapting, and becoming agents of the social spheres in which we participate. At large, a society and its social demands mold us into becoming agents of that society. Literacy and education are at the heart of this social molding, from within the family sphere to the larger social spheres. But how can one reformat all the sociocultural training he/she has received in order to adapt to a new social sphere and simply change, lose, and gain identity? These questions are significant to multicultural societies such as US and Canada, and even more prevalent with respect to immigrant populations. Using autoethnographical data and literature in this area, this paper discusses the issues of immigrant identity and literacy in twofold: a) the lack of attention to immigration and acculturation phenomena; b) the importance of understanding immigrant students' experiences and the need for diversification of teachers and teaching methods, concluding with suggestions for further research.
\end{abstract}

\section{Introduction}

Who am I? Where did I come from? How did I become who I am? What are my roots? Where am I going? Identity is an issue that everyone struggles with on a daily basis. We are constantly changing, adapting, and becoming agents of the social spheres in which we participate. At large, a society and its social demands mold us into who we must become to be respectable agents of that society. Literacy and education are at the heart of this social molding, from within the family sphere to the larger social sphere. When one is born into a social system, adapting is not necessarily an issue. But what about an adult whose social conditioning belongs to another society with very different cultural and social training and conditioning? How can one reformat all the sociocultural training he/she has received in order to adapt to a new social sphere? How can one simply change, lose, or gain an identity? These are the questions my family and I have struggled with as immigrants. Although it has been almost twenty years since we left our native land, there are still cultural barriers that are difficult to cross. This difficulty is more evident for my parents than for me since I was young when we moved; therefore, I am a product of western society in whom only certain eastern cultural practices have been ingrained. But in retrospect, the questions of identity and heritage are more problematic for me as a first generation westernized immigrant woman.

Although these questions may seem more prevalent with respect to immigrant populations, they are relevant to multicultural societies such as the US and Canada that include diverse cultures within their own social frameworks. Thus the issue of literacy and 
identity begin from the microlevel family sphere, or primary discourse (Gee, 1992), to the macrolevel social sphere involving various secondary discourses (Gee, 1992), including the educational systems. To complicate matters more, gender-specific cultural training at micro and macro sociopolitical levels has a great influence on literacy, especially at higher levels. This is complicated even more in the case of adult immigrant literacy, especially with regards to women's education. However, women's struggle in education is not limited to immigrants only, as gender is the central issue affecting their literacy acquisition. Women, whether immigrants or natives, face similar issues with regards to crossing sociocultural boundaries and gaining new identities, except that immigrant women have the additional complexity of alien identity and cultural practices.

This paper discusses the issues of immigrant identity and literacy in twofold: a) it brings forth the lack of attention to immigration and acculturation phenomena, as well as the multifaceted issues of identity, culture, and language prevalent in the lives of immigrants in the US and Canada, with a special focus on immigrant women's education and identity across cultures; and b) it discusses the importance of awareness and understanding of immigrant students' experiences and the need for diversification of teachers and teaching methods to better address the needs of the constantly growing immigrant population. It concludes with suggestions for further research.

The data used for this analysis is autoethnographical: as a first generation female immigrant, I look back at some of the struggles my family faced as immigrants and the trajectory of my experience as an ESL student to showcase some of the prominent struggles faced by immigrants in academic institutions and society at large.

\section{Immigrant Families' Struggles with New Literacies and Identity}

According to Ferdman and Weber (1994), literacy has been portrayed as the "vehicle for social and economic advancement as well as means of enhancing individual lives and fostering equal opportunities" (p. 3). In 1994, Ferdman and Weber examined literacy research across the field and found that although there has been much research done with regards to better understanding literacy and literacy acquisition, most studies concentrate on first-language and mother-tongue literacy, and mainly English literacy in the US. Therefore, they argued, "insufficient attention has been given in this scholarly literature to the particular issues facing people who are immigrants, members of ethnographic minorities, or cross-nationals" (1994).

Ferdman and Weber (1994) assert that the aforementioned categories of people are trying to acquire literacy in English while already possessing a language and a culture from their native land that differ from the literacy and cultural practices that surround them in the US (pp. 4-5). The authors point out that according to the Census Bureau, "in 1990 members of non-European groups, including African-Americans, Latinos, Asians, and Native Americans, accounted for 25 percent of the US population" (p. 5). Bornstein, DeaterDeckard, and Lansford in 2007 stated that 12.4\% of the US populations (approximately 35.7 million people) were immigrants (p. 1). "According to the International Organization for Migration and estimates from the United Nations, in 2000 approximately 160 million people were thought to be living outside their country of birth or citizenship, up from an estimate of 120 million in 1990" (p. 2). Furthermore, based on assumptions that no major 
changes would occur, the US Census Bureau projected in 2004 that by 2030, the number of European-American children will decline by $50 \%$, and the population of Hispanic-American children will rise by $26 \%$, African-Americans by $16 \%$, Asian-Americans by $5 \%$, and Native Americans/Hawaiians/Pacific Islanders by 4\% (Hernandez, Denton, \& Macartney, 2007, pp. 10-11). Regardless of rapid migration across the globe, Bornstein et al. state that "immigration and acculturation phenomena are underresearched and still poorly understood" (p. 3).

As Phinney and Ong (2007) claim,

[w] hen immigrants leave one culture and settle in another, they are faced with fundamental questions regarding who they are and who they will become in the new country. Their ethnic identity, that is, their sense of belonging to their cultural origin, is a key factor in the way they adaptively respond to challenges in their new country. (p. 51)

Most immigrants who come to the US are literate to varying degrees, often possessing literacy skills in more than one language other than English. In order for them to gain citizenship, they are required to acquire literacy in English at a functional level, a process in which culture and identity play a significant role (Ferdman \& Weber, 1994, pp. 10-12). In the case of the more literate and elite categories of immigrants, this struggle is enhanced on a different level. In my father's case, for instance, for an immigrant in his forties with a Ph.D. in Civil Engineering, the struggle to gain access to his professional field in Canada at the same level as his position in Iran triggered an identity crisis for him. To my father, it was a conceptual struggle with pride and identity as he had to start his career from the beginning all over again.

My father's identity crises still remain, as no matter how far he has advanced professionally, and regardless of his superior knowledge in the field and his fluency in English, there is still a linguistic and cultural gap between him and his younger clients. His accent will always speak for him first and his age second. Ironically, this gap is not as evident among the older clients and colleagues regardless of their cultural and linguistic differences. In this case, age and experience seem to pre-empt cultural differences, as the older population can identify with one another in terms of lived experiences and acquired knowledge. My father often talks about his life in Iran in a positive light, as does any adult immigrant I have ever known. Somehow life was always better back home; it had more meaning and it was more pleasant. Every immigrant was always "somebody important" back home, wherever that home may be. This is the same in the case of any older person, as the hardships of youth seem not so hard with the passing of the years. The past is always sweeter for the immigrant, because it owns that native culture in which their identity was formed. The question I always pose in response is, "Then how come you moved?" And often the answer is, "To give my kids a better life," or "Life was better but the government would not leave you alone." And sometimes the answer is a simple "I don't know. I ask myself the same question." Thus, sadly, even though immigrants may be very literate and knowledgeable in their own culture and language, they are often not regarded as such by English-speaking society. 
Likewise, the children of immigrants face the issue of identity and cultural struggle, but this struggle is intensified since the culture is threefold between their parents' culture, that of the current society in which they live, and their own culture, one that sets them apart from those cultures they defy. As one belonging to this category, I continue to struggle with the concept of culture and identity. Growing up "different" is not an easy task. When you are "different" from your parents, from your classmates, from your cousins, and the conflicting social circles through which you move, a struggle with identity is inevitable, especially as you grow older.

The identity of adult immigrants is a complex issue. Immigration is often a result of a desire to improve one's life and living situation, which includes removing oneself and one's family from a hostile environment. But while improving or saving their lives in one way, immigrants lose a lot as a result of their immigration, including much of their literacy skills and their identities. Immigrants who were sufficiently literate in their homeland are forced to acquire new literacies and identities, a new language and culture, as they adapt to their social surroundings.

As Phinney and Ong (2007) argue, the immediate family sphere is where ethnic identity is formed and cultivated. The family environment provides the foundation for the formation of identity, especially in the case of children and adolescents (pp. 55-57). In addition, Phinney and Ong assert that ethnic identity continues to form in relation to school, community, and professional spheres as well as historical context (p. 57). Often immigrants find comfort in forming new communities with similar backgrounds, and find relief in helping one another improve their lives as immigrants and developing the necessary literacies for their advancement. The authors agree with Rosenthal and Hrynevich (1985) that "more cohesive and well-structured communities contribute to stronger ethnic identity" (p. 57). However, at the same time that they belong to a certain marginal community, immigrants struggle to become part of the larger social sphere and acquire the necessary literacy, cultural, and linguistic skills required to tap into the world of the middle-class American social sphere. Even if one is able to rise above the social conditionings and acquire the academic, social, and political literacies of middle-class American society against all sociocultural economic odds, he/she will always continue to struggle, as his/her primary discourse is at odds with his/her secondary discourse. This struggle may not be evident professionally because it is personal with regards to one's ethnic and sociopolitical identity.

Adapting is often not a smooth transition, if a transition at all; rather, immigrants may look for ways to simply cope and deal with their struggles. This sense of loss and lack of meaning-making is a part of immigrant life. However, even though identity crisis has its roots in many domains such as cultural, social, and political, language always remains at the core. Language, according to Bonny Norton (2010), "is not conceived of as a neutral medium of communication [as poststructuralists claim], but it is understood with reference to its social meaning, in a frequently inequitable world. It is this conception of language that poststructuralists define as 'discourse'" (p. 350). Immigrants gain agency within the dominant culture through the acquisition of language and appropriate discourse. In his history of sexuality, Foucault (1978) describes dynamics of power relations and discourse. "Power," Foucault argues, 
must be understood in the first instance as the multiplicity of force relations immanent in the sphere in which they operate and which constitute their own organization; as the process which, through ceaseless struggles and confrontations, transforms, strengthens, or reverses them; as the support which these force relations find in one another, thus forming a chain or a system, or on the contrary, the disjunctions and contradictions which isolate them from one another; and lastly, as the strategies in which they effect whose general design or institutional crystallization is embodied in the state apparatus, in the formulation of the law, in various social hegemonies. (pp. 92-93)

Power in this sense, in the case of immigrants, is gained through reinforcing and strengthening identities within the family and community spheres, as well as learning literacy skills that would gain them access to the dominant discourse (Gee, 1992).

In retrospect, these difficult situations for adult immigrants affect their children's lives in many ways. The children's identities are formed within the home sphere and outside of it, two conflicting spheres in many respects. The struggles may push the children to work harder to become a part of middle-class society by acquiring the necessary literacy to gain access to that social sphere. Some may move away from the idea of empowerment through literacy by "keeping it real" and remaining within their social communities, protecting what has become their new identity, while others may not have the chance to pursue an education due to economic difficulties.

\section{Immigrant Women's Identity and Education}

In her article "Social Identity, Investment, and Language Learning," drawing on the poststructuralist conception of social identity, Norton (1995) puts forth a "theory of social identity which assumes that power relations play a crucial role in social interaction between language learners and target language speaker" (p. 12). She outlines deficiencies of the theories in second language acquisition (SLA) due to their failure to conceptualize the relationship between the individual language learner and the larger social context that affects the process of language learning (p. 10). She further argues that this disagreement in SLA scholarship should not be dismissed, and suggests that "this confusion arises because artificial distinctions are drawn between the individual and the social, which lead to arbitrary mapping of particular factors on either the individual or the social, with little rigorous justification" (p. 11). While outlining the gaps in SLA theories and calling for the reconceptualization of the SLA theory of the individual, Norton suggests that the language learner's introversion or silence in the second language should be looked at in terms of the social context, which can affect the learner's self-confidence and worth and either encourage them to speak or mute them (pp. 11-12).

In support of her social identity theory, Norton (1995) provides an account of her research in 1990, a case study of the language learning experiences of five immigrant women: Mai from Vietnam, Martina from Czechoslovakia, Felicia from Peru, and Eva and Katarina from Poland. Norton's research was focused on addressing two major questions: (1) The available opportunities socially structured outside the classroom for immigrant women in Canada to practice and use English, their responses to the social opportunities to 
create, use, or resist the use of English, and to what extent their actions in taking or avoiding opportunities to practice English could be understood with regards to their investment in English or their changing social identities; and (2) how could this enhanced understanding of social identity and natural language learning of immigrant women inform SLA theory and ESL pedagogy in Canada? (pp. 13-14).

Norton (1995) indicates that motivation to learn English was not a concern among these women, as they all went to extra lengths to take courses and participate in this diary study, as well as indicating a desire to have more social contact with Anglophone Canadians. Moreover, Norton explains that all the women, except Martina, expressed comfort speaking English with friends. However, Norton found that all five women were uncomfortable conversing in English with people in whom they had "a particular symbolic or material investment." "Eva, who came to Canada for 'economical advantage', and was eager to work with [A]nglophones, practice her English and get better jobs, was silenced when the customers in her workplace made comments about her accent." Mai, who felt her future, job security, and financial independence were in the hands of management, was most uneasy conversing with her boss. And Katarina, who escaped from a communist society, was stressed by speaking English with her Anglophone doctor, teacher, and professionals. For Martina, who occupied a surveyor's job in her own country and immigrated "for her children," her frustration lay in her inability to "defend her family's rights in the public world," while Felicia from Peru, "who had come to Canada to escape 'terrorism,' and had great affective investment in her Peruvian identity," felt uncomfortable speaking English in front of fluent Peruvian English speakers (all quotes p. 19).

Norton's research shows that power dynamics play a crucial role in the formation of social identity in a particular discourse. In the case of Felicia, the Peruvians who have advanced linguistic skills have gained access to the dominant discourse which Felicia struggles to reach. Her feelings of discomfort relate to her identity as a Peruvian who has not yet acquired the language other members of her ethnicity have mastered. Furthermore, Norton's research outlines the multiplicity of immigrant women's identities, from the private family sphere to the many social spheres in which they participate. For instance, in Martina's case, whose identity as a primary caregiver was the driving force of her investment in English, her central concern was burdening her children with "taking on more public and domestic tasks than were absolutely necessary" (p. 21) due to her struggles with English. Norton points out that primary caregiver is only one of the multiple sites that affect the formation of Martina's identity; others include being an immigrant, a woman, a mother, a language learner, a worker, a wife, etc. Norton's case study supports her argument that "the individual language learner is not ahistorical and unidimensional but has a complex and sometimes contradictory social identity, changing across time and space" and that "motivation is not a fixed personality trait but must be understood with reference to social relations of power that create the possibilities for language learners to speak" (pp. 25-26).

Norton's arguments are not limited only to language learners, but apply to all learners in general. The multiplicity of adult identities and social conditionings that contribute to the formation of individual identity is what scholars like Bourdieu (1987), Gee (1992), and Anderson (1994) have emphasized and made the basis of their theories. 
Bourdieu (1987) asserts that a language learner's habitus must be taken into account in order to provide a more inviting and effective environment for acquisition.

According to Anderson (1994), the "reader's schema, or organized knowledge of the world, provides much of the basis for comprehending, learning, and remembering" ( $p$. 465). And Gee (1992) defines "discourse" through its association with language, thinking, and acting within a social network. One of the most important factors Gee points out is that "discourses are inherently related to the distribution of social power and hierarchical structure in society" (p. 14). Thus, the importance of mastery of certain discourses is magnified in society in order to attain control over a certain medium and gain social and/or political power. In the case of immigrants, women in particular, whose primary discourse does not match the dominant secondary discourse, access to this discourse is far more difficult than for native speakers.

It is important to note that the women in Norton's case study mostly come from European cultural backgrounds, which makes their cultural transition much easier than those from entirely different cultural spheres such as the Middle East. These women are just a few among the massive numbers of immigrants who struggle to form, defend, and gain identity and space in their new social sphere.

The issue of immigrant struggle and identity crisis is not a newly recognized phenomenon. In a case study conducted by Shiva Sadeghi (2008) on immigrant Iranian students in Canadian institutions of higher education, she found commonalities in the underlying themes of the six female participants' experiences and the meanings they all attributed to these experiences. Sadeghi states that the "desire for 'learning'-influenced by complex and intertwined interactions between their cultural values and perceptions and their unique historical and social stances as women and first-generation immigrantsseemed to play an important role in the lives of these six women" (p. 221). The results of the study further indicated that the new country presented women with the opportunities to "redefine their roles" with regards to their multiple sites of identity "as women, mothers, wives, daughters, and educated individuals; however, their immigrant status was intertwined with complexities of living and learning in the margins of the new country" (p. 222). In retrospect, Sadeghi's research also showed that their efforts to "renegotiate their new identities as educated women in the face of traditional cultural images as housewives meant that these women found themselves at the periphery of their families, often questioning, objecting, and resisting men's domination" (p. 222).

\section{Immigrant ESL Students in the Classroom}

To be multicultural is to be diverse, which is the foundation of today's societies in North America, Australia, and parts of Europe. Thus, these societies demand diversity in all aspects of social and professional life; the United States in particular has one of the largest multicultural populations in the world. And yet we struggle to meet the educational demands of our multicultural society, even though we continue to accept new immigrants and refugees that add to the rich makeup of our heterogeneous culture. So the question that has been raised and explored by many researchers remains: how can we teach ESL or bilingual students whose dominant language is not English and address the learning needs 
of such students in multicultural classrooms? Furthermore, what teaching methods could be applied to encourage the progress and learning of these students?

Based on the literature review and my personal experience as an ESL student exposed to and influenced by several cultures, I find the classroom to be the most crucial place that affects and encourages or discourages students' linguistic and academic learning. Even if students have strong family support encouraging their academic progress, what takes place in school can solidify the learning process or disintegrate it and cause students to become introverts and avoid recognition of their skills and potentials. This section emphasizes the importance of three elements that can potentially improve language learning process of ESL students and ultimately, success in school: (1) utilizing narrative as a cultural and personal exposure to understand students' backgrounds and learning foundations, as well as triggering investigation and communication of their cultural capital (Bourdieu, 1987) and further exploration of their related interests; (2) teacher-student relationships, understanding, and trust, (3) teacher training in cultural studies and diverse teaching methodologies that target multicultural classrooms.

In her article "Barriers to Meaningful Instruction for English learners," Lois Meyer (2000) discusses the obstacles that hinder effective instruction for ESL students who face linguistic and cultural difficulties in the classroom. Meyer begins her discussion by stating, "[t]he English learner sits in class, not completely understanding or fluently speaking English and possessing limited experience with the cultural practices and expectations of school," and goes on to ask:

What is it like for this student to go to school in English only? When the learner's language is not the school's language, how does he or she feel when confronted with academic lessons, school texts, and classroom learning activities that are partially or totally incomprehensible? (p. 228)

As a scholar, I consider myself lucky in having the ability to answer all of these questions and more, as I was the unfortunate culturally shocked ESL student who sat in many classrooms without understanding the subjects being discussed. Numbers were my savior and words my enemy. Reading aloud was a horrendous experience that caused me nightmares each night. And though science was interesting and exciting, the language barrier caused difficulty in comprehending directions and explanations, which manifested itself in negative instructor and peer commentaries and dreading the classes entirely.

Few mainstream educators can comprehend the magnitude of confusing experiences the individual ESL student goes through based on their personal background and change in habitus, a concept that, according to Bourdieu (1987), refers to a person's disposition and beliefs based on personal environment and experience that condition a person to act and think in a certain way. ${ }^{1}$ However, by examining individual cases, we can gain a glimpse of their experience and better understand their needs in order to design

\footnotetext{
${ }^{1}$ As Bourdieu stated,"The habitus entertains with the social world which has produced it a real ontological complicity, the source of cognition without consciousness, of an internationality without intention, and a practical mastery of the world's regularities which allows one to anticipate the future without even needing to posit it as such" (quoted in Kramsch, 2008, p. 38, see also Kramsch, 2009).
} 
teaching strategies and learning environments that encourage their progress and remove the negative labels and connotations attached to their learning process. After all, the immigrants of today build the future of our nation. Thus, I will conduct this investigation through an autoethnographical examination of my own literacy process as a young girl in Iran and an Iranian ESL Middle School student in England, and briefly discuss two negative literacy experiences as an undergraduate immigrant student in Canada, and an adult US immigrant in graduate school. Removing myself from the context, I will briefly examine a poem I wrote in English at the age of 13 after less than a year of being exposed to English, in order to assess cognitive process and cultural background and experience.

\section{Literacy and Linguistic Autoethnography Education in the Islamic Republic of Iran}

My personal memories of Iran among family and friends, behind closed doors where the Islamic government did not have the opportunity to impose and suck the joy out of life, are happy ones. I had a rich childhood with a scholarly family who encouraged academic and social learning and personal growth. However, school was another story. My education in Iran from first to sixth grade consisted of rigorous memorizations and tests almost every day. This education system was very much what Freire (1970) calls a banking system, where the teacher was the depositor, the mechanical narrator of abundant information, and the students were the depositories, the pit into which teachers dropped information and expected its regurgitation the following day on a test (p. 79). Not much communication in terms of critical thinking or discussion of subjects that triggered cognition or the invention and reinvention of knowledge took place in the classrooms.

When it came to religious and social studies courses, the material would become frustrating and the tests themselves nonsensical since the correct answers were those of the teachers' and the books'. Questioning the logistics was dangerous, especially pertaining to theology. In fact, if teachers discussed anything, it was to relay what we "should" believe and know according to Islamic laws; to question Islam and its laws was to question the faith and god, which was a sin. Freire's (1970) statement that the "banking concept of education, which serves the interests of oppression, is also necrophilic" (p. 77) is a perfect description of this teaching methodology.

Cultural Studies was exposure to cultural norms within the Islamic Iranian social sphere and excluded pre-Islamic history and culture or non-Muslim Iranians. Further, with the exception of other Islamic countries, Europe and the Americas were the evil "others" whose cultural norms were in conflict with those of the Islamic Republic. As Freire (1970) argues, "[o]ne of the gravest obstacles to the achievement of liberation is that oppressive reality absorbs those within it and thereby, acts to submerge human beings' consciousness" (p. 51). Needless to say, students did not, and, as we can witness from the events taking place in Iran today, do not have a voice. In fact, they are dehumanized if they attempt to gain a voice that does not promote the Islamic Republic's ideals, and are severely and violently discouraged by the government of having or portraying different perspectives. This is the concept of dehumanization of the oppressed stressed by Freire $(1970$, p. 88). This is not to say that Islam itself dictates such a teaching methodology. In fact, pursuit of knowledge is very much promoted and encouraged in Islam. Further, the implementation 
of such teaching methodology as well as inhibition of access to various kinds of knowledge does not prescribe to the Islamic doctrines about pursuit of knowledge.

\section{Move from Islamic Republic of Iran to England}

At the age of twelve, I moved to England, where I was first exposed to the English language in a West-Midland Black-country accent. At first, it was very difficult to learn this language as the people around me spoke English in a very different accent than my parents. Whatever my parents taught me would help others understand me but did not help me understand anything anyone else said. The change in social location and lack of knowledge about the new location caused much confusion and displacement. It took about six months for me to become somewhat fluent in English and learn to understand the black-country dialect and recognize the differences between various English accents.

According to Campano (2007), in contrast to the "subtle yet pervasive image of the ideal student," there is "the less-than-ideal student, whose education is framed as a series of problems: of language, cultural integration, parental participation, school readiness, and classroom decorum, to name a few" and in his experience it was often "the poorer students from immigrant, migrant, and refugee backgrounds" who did not fit into the misguided ideal. Campano indicates that they received various instructional and social interventions that "often barred these students from the kinds of rich curricular experiences necessary for success in higher education and beyond" (both quotes, p. 49).

This was certainly the case for me in the first two years of my schooling in England. The school I attended did not have a program for nonnative English speakers; in fact, I was the first student at that school who could not speak English. Thus, I was the problem child with close to zero level of comprehension, and as a desperate resort, the Headmistress assigned a male teacher to work with me individually in all subjects. It was ironic that the Headmistress paid no consideration to my cultural background and experience in assigning a male instructor to a girl freshly arrived from a rigid Islamic country that did not allow for male-female interaction. Regardless of the discomfort caused by the instructor's gender, our method of communication was through drawings and numbers, and as I remember, he was not a very talented artist! Furthermore, this instructor, who I believe was ignorant of the negative effects, constantly made me aware of my deficiencies in language and caused me much humiliation by chuckling or showing signs of frustration as I made mistakes. However, he tried very hard to trigger communication and understanding.

Meyer (2000) notes that "there are predictable areas of confusion for Limited English Proficient (LEP) students any time an academic lesson is taught through English." If the teacher does not do the instructional work to "help construct their understanding and participation," these lessons will be "confusing and even overwhelming" for the students (p. 228). The time I spent with the instructor was certainly confusing and frustrating. Had the instructor been female and had there been some formal language instruction instead of free-form language learning, and planned lessons with the instructor on subjects such as science, geography, and math, which were familiar to me, I believe learning at a productive and cognitive level could have been achieved through one-on-one instruction. Furthermore, the instructor could have asked me to draw something that represented my life, background, or interest in order to tap into what Bourdieu (1987) calls "cultural 
capital" and Meyer (2000) refers to as "funds of knowledge" (p. 230). By utilizing my experiences, asking me to narrate through drawings, and attempting to explain the stories or events, the instructor could have given the impression that he valued my personal knowledge, what I had already learned and experienced, which would have triggered my interest and enthusiasm to communicate something about myself and encouraged higher cognitive learning.

When the method of one-on-one instruction failed after a few weeks, the Headmistress's next strategy was to place me in the same classrooms as native English speakers with this instructor by my side as a personal tutor. Thus, I sat there in classes such as history, religion, English, and science where the teacher spoke a language I did not comprehend and did not require me to participate. I was a nonentity among the learning students.

At first, having the instructor there with me was comforting, but I soon realized that his presence caused me much grief and made me the subject of ridicule. As a result, the instructor was removed from classes in which his presence might not be needed as much. I was stuck in classrooms where I failed to comprehend the content and was completely unable to participate in class projects, too afraid to raise questions, and failed to engage in discussions. Thus, not having access to the dominant language (Gee, 1992) excluded me from the dominant discourse academically and socially.

With the move, my environment changed dramatically and I experienced drastic culture shock. I now sat in a coed classroom where boys and girls passed notes and commented on each other's physical attributes. I tried to avoid the boys and their comments and could not relate to the girls in my class. Based on my habitus at the time, my classmates' behavior seemed disrespectful to each other, to the teachers, and to their families. They would openly discuss their families and express hatred towards them; they swore at each other and their parents, and all their dilemmas and hardships centered on rejection from the opposite sex and discipline from their parents. I remember thinking that none of these children would survive if they were in Iran during the war. They would not know how to act when the bomb-siren went off and they would certainly face detention with severe consequences for speaking and behaving this way. This was a massive culture shock and made it increasingly difficult for me to communicate with the other children, as we were so different and did not understand each other's behavior.

In terms of fitting in socially, there were two categories of girls: the popular girls who wore shorter skirts (though we had uniforms) and makeup, and flaunted themselves at boys, and the timid girls who were categorized as the "nerds" because they paid attention in class and spoke "correctly." I fit in neither category at this time, since I was trying to learn the English language and just survive. I still had the nightmares of war and the memories of being almost kidnapped three times. However, the nightmares of school and failure to speak to my peers and not doing well in class and saying the wrong thing or mispronouncing a word and getting laughed at, were now part of those nightmares.

Nonetheless, the teaching methodology in England, which was a problem-posing method (Freire, 1970) where the teachers present students with a problem and encourage students to provide various solutions to it, was refreshing; and even though I did not speak 
the language, I was able to learn through practice. Ironically, my English class was always my favorite and my most dreaded period as I had the opportunity to read, comprehend, and practice writing but detested reading aloud. After reading the poems of William Blake and William Butler Yeats, Mr. Yeats, my English teacher, encouraged us to write a poem. The following was mine.

\section{Wish for Peace (1992)}

Every night in my sleep

I live in a world of dreams.

In this world of dreams, Whatever I have seen, Is nothing like reality;

There is no responsibility. There's no gun; there's no blood;

Everything is fine cut.

In this world there are no cars,

No pollutions, just stars.

Everywhere is filled with joy, Children's laughter, rock ' $n$ ' roll!

Everyone is left in peace, No kidnappers, nor a thief. Everyone's proud and happy, Like I said: "nothing like reality."

Everyone's like they seem In this wonderful dream.

Then again, it's all a dream!

Does it have to be like this? Filled with anger, not with peace? The real world, that's what I mean,

Does it have to be so mean? Filled with rage and gun-machines, Blood's everywhere like a stream.

Children crying out, begging for mercy, Just want to have a home amongst their family.

Parents are crying who lost their loved ones,

Cursing the people who brought them the song

That says: "fighting for your country

Will bring you dignity."

But all it does is to bring

Pain to the hearts of their family. 
Why should we fight?

Why should we kill?

To bring power just to thrill

The people who want more power

To rule the world and build their tower.

We are killing real people

To get one thing out of it all

And that one thing is more power

Which has never lasted forever.

If I could, I would remain

In my own world all the same.

But I know whatever I may see

In this world, can never be.

Because all this that I see,

Is nothing more than just a dream.

Removing myself and examining the content, I am speechless at my ability to express so much in one poem. This is a morbid poem written from a 13-year-old's perspective that portrays the student's experience of chaos, responsibility, pollution, death, and war; something of which many of our US born children and adults have no conception today. As Campano (2007) states, "stories have an obvious interpersonal value because they enable students to weave their unique histories into the fabric of the classroom community" (p. 50). Thus, recognition and utilization of students' cultural capital to build cognitive progress is very important. Were this submitted to me by a student, I would be able to recognize some of the student's experiences and his/her background, and would have encouraged the student to further develop those experiences in prose perhaps, or investigate the history of the war and express his/her opinion on it, and so on.

Of course it is very difficult to relate to such a student as a teacher who has no conception of the magnitude of emotional scarring such experiences can leave. So, how could a teacher teach this student without having the ability to relate to his/her experiences? My teacher's response, as I remember, was that I had done a good job with writing and I had advanced so much in English. Though he was encouraging, his response was inadequate in raising my interest to continue this project.

Luckily my teachers were fascinated by me; I was an unusual case, a chance for experimentation. My homeroom teacher, who was also my English teacher, used various methods to encourage my learning through writing. Although he did not tap into my cultural capital, his praising of my progress was encouragement enough to keep me on track. However, my mother was the real driving force behind my academic learning progress. As Orellana and Gutiérrez (2006) suggest, we must challenge the notion of an individual's separability from his/her context and encourage integration of primary and secondary social spheres of the nondominant and immigrant student. This promotes development of individual identity and progress of the nondominant individual through the use of personal domain and experiences, as well as school-dominated experiences. My mother, being an academic, emphasized the importance of academic progress and 
therefore, my primary discourse was only different from my secondary discourse in language; and even that difference my mother worked hard to minimize. Thus, through the integration of my primary and secondary spheres, I was able to overcome language and cultural barriers, gain access to the dominant language, and succeed and excel in school.

\section{Mastering the Dominant Discourse}

According to Gee (1992), "discourses are inherently related to the distribution of social power and hierarchical structure in society" (p. 14). Thus, the importance of mastery of certain discourses is magnified in society in order to attain control over a certain medium and gain social and/or political power. Gee explains that in order to control discourses, one must acquire and learn those discourses, and that middle-class children acquire literacy within their family sphere (primary discourse) and develop meta-level cognition through learning at school (secondary discourse). However, it is questionable whether this rich acquisition and learning combined for the ESL student can be powerful enough to tap into the dominant discourse without discrimination. Even though I had managed to learn the dominant literacy and language at school, was fortunate to acquire both the dominant academic and social literacies from my family, and had access to the dominant discourse, I still encountered numerous obstacles due to being a nonnative English speaker and the "other" in both undergraduate and graduate school.

During my second year of undergraduate studies in a Canadian university, I had a conflict of opinion with one of my male professors over having cited a work inaccurately in one of my papers. In our meeting in his office, he observed me from head to toe and questioned my academic achievements saying, "I don't know what you do for your other professors to get the As and Bs you have on your transcript, but you are not receiving an A from me and I don't think you can make it as a journalist. I highly encourage you to rethink your future aspirations." His words still echo in my head. When I reported this incident to the Dean, she seriously discouraged me from pursuing it any further as he was a prominent professor and I could not provide an audio recording of his comments. The Dean emphasized that it would affect my relationship with the other professors in the department if I decided to pursue the matter. She indicated that she had dealt with similar complaints from several female students in the past about this professor and they similarly decided to drop their pursuit.

At that point I realized that I had overcome so much to reach this stage, to be an English literature major and do so well, and yet having access to the dominant discourse was not enough. There were still many social and political barriers to overcome. What seemed ironic to me was that this professor was a second-generation immigrant and not from a highly educated family, as he had confessed in class. And yet, he questioned my abilities for academic success, not based on my academic performance, but based on my gender and his notion of my inability to cite accurately, which was due to his lack of teaching the matter in class. It was amazing how indiscreet this professor was about his gender bias. He only addressed the boys in class and praised them for their accurate interpretations of poems, which were in line with his own; the girls were just bodies filling the seats. Obviously such teachers should not be in classrooms, as they hinder learning and discourage progress. But what can be done when the system provides support for such 
professors to flourish in the field and Deans support them by scaring students and discouraging them from filing complaints against them?

Even as a graduate student who had learned to negotiate the dominant discourse by gaining access to the language and culture, socially and through education, and had become a part of it, I was faced with discrimination based on being a nonnative speaker, and one whose writing style was not up to par with the American standard. At this time, when I inquired about my B+ grade on a paper, after her many attempts to give valid reasoning of her grading process, my professor in an aggravated tone indicated that it was evident from my writing that I was not used to the American composition style, which was the appropriate form of discourse at that university and in the US. She indicated that the British and Canadian narrative styles leaked throughout my paper and this was not the desired assertive discussion form. Therefore, in order to succeed there, I had to change my writing style and adopt a more aggressive American tone. Though I do not think that this professor's comments were ungrounded, I believe her strategy for addressing the importance of conforming to a specific composition style in order to become part of the discourse was not that helpful. Constructive criticism would have gone much further in helping me address what she termed my weakness. Instead, I walked out of her office feeling completely inadequate as a writer, and this feeling lasted through the first two semesters of my graduate studies.

When thinking about my linguistic autobiography, it is hard to narrow down what specific events in my life influenced the development of my language. In fact, my language skills are still evolving. I am forever the ESL student who has moved between countries and continents and still struggles with perfecting her knowledge of one language. However, even though English is my adopted language and secondary discourse, I am most fluent in and comfortable with English. This is because I adopted English as my dominant language and sometimes use it even in my primary discourse with family and friends. I sometimes still feel inadequate compared to my colleagues who have had the benefit of learning English and its structure since childhood in a single dialect or culture, whereas I have had to learn, adopt, and use three different dialects of this language: British, Canadian, and American, and all of the subdialects within each culture. This feeling of inadequacy is the result of years of humiliation and negative commentaries and categorization as an ESL student. Ironically, it is this feeling of inadequacy that had driven me to learn and strive to access and become a part of the dominant discourse. Paradoxically, I spent five years of my graduate career teaching undergraduate students how to properly use the English language in their compositions in a professional context. Thus, as a nonnative English teacher and researcher, I am interested in investigating the struggles of nonnative English learners and ESL students in order to develop teaching strategies that improve the learning experience and growth of these students.

\section{Emphasis on Implementation of Strategies to Encourage ESL Students' Learning}

As discussed earlier, narrative is a powerful way to tap into the ESL, immigrant, and socioeconomically disadvantaged students who do not have the benefit of a correlation between their primary and secondary discourses. A poem or a personal narrative reveals a great deal about its author and can be used as a stepping stone for the student's utilization 
of their cultural capital to access the dominant discourse. As Campano (2007) stresses, "[o]ne purpose of inviting the students to share their stories is to better understand how the students can use their background knowledge to gain access to curricular content" ( $p$. 50).

It is apparent that none of the teachers I encountered in England had training in teaching ESL students or in multicultural classrooms. Lack of training and preparation causes frustration and confusion for both the students and the teacher and vastly hinders students' learning. As Meyer (2000) discusses, lack of cultural knowledge is a great barrier to effective instruction. Exposure to various cultures and practices through teacher training and academic courses on various cultures is an excellent way to enhance teachers' understanding of students' cultural and social capital. Furthermore, adopting critical literacy in the classroom, especially from the elementary level, is crucial to students' development and cognitive process. As Lewison and Harste (2008) assert, research shows that implementing critical literacy in the classroom starting at the elementary level results in students' increased engagement with the topic and its exploration, triggering more substantial classroom discussions and increasing students' success level as they become critical thinkers and learners. Narrative can be the first step to critical literacy.

\section{Implications for Research}

This paper has outlined some of the leading discussions surrounding immigrant literacy and identity, focusing on women and their negotiations of their identities as they begin their struggles as immigrants. Although there is vast research in the field of immigrant identity and literacy, the focus seems to rest on immigrant families' struggles in the new country in terms of attaining literacy, negotiating identities, and crossing boundaries. Furthermore, scholarship seems to focus predominantly on dealing with immigrant children's identity and motivation to pursue education in schools. However, there is still a demand for extensive research in this area that would encourage changes in policies and curriculum to address the needs of our multicultural classrooms.

With regards to immigrant adult literacy, what is seen in the literature seems to center on the deficits of second language learners' acquisition, whether individually or socially. More research needs to be conducted on the positive aspect of immigrants' struggles that motivate and lead to individual desire for higher education and success in the new sociocultural sphere. My research has led me to the belief that there is a major gap in scholarship with regards to examining the struggles of highly literate adult immigrants. I believe there is a need to examine highly educated immigrant families, their position on education, and their struggles with attaining access to the dominant discourse and succeeding in the new society. Is Bourdieu's theory of agreement of primary and secondary discourses leading to success in the dominant discourse correct in the case of educated immigrants even though they are second language learners? It seems that once they are considered to have access to the dominant discourse in one society, their struggles appear less relevant compared to the immigrants from lower socioeconomic and cultural spheres. What is more, the education of the intellectual immigrants often does not gain them status in the new country. In a way, their struggles with identity and displacement are far more complex than those of the working class. This was certainly the case for my family. 
Furthermore, in the case of the adolescent children of highly educated immigrants, the pressures of gaining access to dominant discourses and succeeding in pursuit of higher education add to their struggles to learn the language and succeed as immigrants in the new country without losing their heritage and cultural identity.

Sadeghi's (2008) research presents an important aspect of immigrant desire for higher education in relation to attaining individual and social agency and power by entering the dominant discourse. Education in past 20 years has presented a new avenue for the immigrant women who seek to overcome the struggles of being in a foreign sociocultural setting and breaking the cultural boundaries of their identity as only the mother, wife, and caregiver in the family by becoming an active participant in the larger sociopolitical sphere through gaining access to and engaging in the dominant discourse. In my own case, having experienced the pressures of succeeding in the academic world by following in the footsteps of my immigrant parents, I find myself extremely challenged in trying to balance between time, sociocultural spaces, and various sites of identities. I am an Iranian woman who married an American; and as a mother, I struggle to raise my children as bilingual American-Iranians while trying to instill certain cultural values, among which is the emphasis on education. As a wife, I struggle with power relations with my husband in the household, as I see my role in the family and social sphere equal to his, if not greater. As a strong and educated woman, I struggle to keep up with my social identity when difficulties in the family sphere influence my performance and participation in the social sphere. As a product of my cultural and family upbringing, I see no other choice than to raise my children with the belief that they must attain the highest level of qualification possible in their desired profession and leave no room for negotiation. And finally, as a professional, I see the problems with such strong beliefs and assertions on my children's future identities and place in society.

The American ideal of being who one wants to be did not apply in my case, as my parents always emphasized that being who one wants to be should be following the desire to reach the highest level of knowledge in the path one wants to pursue. Value of one's identity in Iranian culture is measured by one's knowledge and qualifications in that culture. This belief is ingrained in the child at an early age, which becomes the most important factor of shaping that child's identity with regards to the position they hold in society.

Having briefly discussed the complexities of my own identity formation as a firstgeneration Iranian immigrant woman and the child of highly educated immigrant parents, and having witnessed the same phenomena in my culture with other Iranian immigrant families, I see a great need for more research in this area. In order to understand the immigrant experience and identity, all classes of immigrant populations need to be studied. Therefore, examination of the educated immigrant population's adjustment to the new sociocultural sphere and workplace with limited language acquisition or questions of identity is needed to show how this affects the education of second-generation immigrants. Finally, I propose that in order to better understand the social practices of immigrants and their struggles in the new country, such research should be approached from a cultural studies perspective in order to effectively examine the integration of cultural identities with regards to educational training. 


\section{References}

Anderson, R. C. (1994). Role of the reader's schema in comprehension, learning, and memory. In R. B. Ruddell, M. R. Ruddell, \& H. Singer (Eds.), Theoretical models and processes of reading (4th ed., pp. 469-482). Newark, DE: International Reading Association.

Bornstein, M. H., Deater-Deckard, K., \& Langford, J. (2007). Introduction. In J. Langford, K. Deater-Deckard \& M. H Bornstein (Eds.), Immigrant families in contemporary society (pp. 1-6). New York: Guilford Press.

Bourdieu, P. (1983). The forms of capital. In J. G. Richardson (Ed.) Handbook of theory and research for the sociology of education. Westport, CT: Greenwood Press.

Campano, G. (2007). Honoring student stories. Educational Leadership, 65(2), 49-54.

Ferdman B. M., \& Weber, R. M. (1994). Literacy across languages and cultures. In B. M. Ferdman, R. M. Weber, \& A. G. Ramírez (Eds.), Literacy across languages and cultures (pp. 3-29). Albany: State University of New York Press.

Foucault, M. (1978). The history of sexuality: An introduction (vol. 1; R. Hurley, Trans.). New York: Random House. (Original work published in 1976).

Freire, P. (1970). Pedagogy of the oppressed. (M. B. Ramos, Trans.). New York: Continuum.

Gee, J. P. (1992). What is literacy? In P. Shannon (Ed.), Becoming political: Readings and writings in the politics of literacy education (pp. 21-29). Portsmouth, NH: Heineman. (Original work published in 1987).

Hernandez, D. J., Denton, N. A., \& Macartney, S. E. (2007). Family circumstances of children in immigrant families. In J. Langford, K. Deater-Deckard \& M. H. Bornstein (Eds.), Immigrant families in contemporary society (pp. 9-29). New York: Guilford Press.

Kramsch, C. (2008). Pierre Bourdieu: A biographical memoir. In J. Albright \& A. Luke (Eds.), Pierre Bourdieu and literacy education (pp. 50-67). New York: Routledge.

Kramsch, C. J. (2009). The multilingual subject: What foreign language learners say about their experience and why it matters. Oxford: Oxford University Press.

Lewison, M., \& Harste, J. C. (2008). Creating critical classrooms: $K$-8 reading and writing with an edge (pp. 1-23). Hillsdale, NJ: Lawrence Erlbaum.

Meyer, L. M. (2000). Barriers to meaningful instruction for English learners. Theory into Practice, 39(4), 228-236.

Norton, B. (2010). "Language and identity." In N. H. Hornberger \& S. McKay (Eds.), Sociolinguistics and language education (pp. 349 - 369). Clevedon, UK: Multilingual Matters.

Norton, B. (1995). Social identity, investment, and language learning. TESOL Quarterly, 29(1), 9-31.

Orellana, F. O., \& Gutiérrez, K. D. (2006). What's the problem? Constructing different genres for the study of English learners. Research in the Teaching of English, 41(1), 118-123. 
Phinney, J. S., \& Ong, A. D. (2007). Ethnic identity development in immigrant families. In J. Langford, K. Deater-Deckard, \& M. H. Bornstein (Eds.), Immigrant families in contemporary society (pp. 51-68). New York: Guilford Press.

Sadeghi, S. (2008). Gender, culture and learning: Iranian immigrant women in Canadian higher education. International Journal of Lifelong Education, 27(2), 217-234. 